\title{
2002s-84 \\ Models for Bundle Trading in Financial Markets
}

\author{
Jawad Abrache, Teodor Gabriel Crainic, \\ Michel Gendreau
}

\begin{tabular}{c}
\hline Série Scientifique \\
Scientific Series
\end{tabular}

\section{Montréal}

Octobre 2002

(C) 2002 Jawad Abrache, Teodor Gabriel Crainic, Michel Gendreau. Tous droits réservés. All rights reserved. Reproduction partielle permise avec citation du document source, incluant la notice (C.

Short sections may be quoted without explicit permission, if full credit, including $@$ notice, is given to the source.
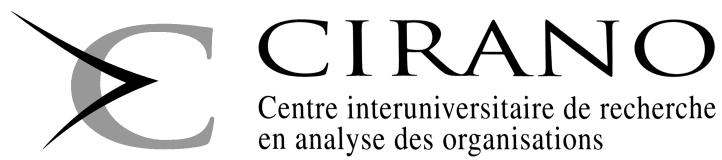

Centre interuniversitaire de recherche en analyse des organisations 


\section{CIRANO}

Le CIRANO est un organisme sans but lucratif constitué en vertu de la Loi des compagnies du Québec. Le financement de son infrastructure et de ses activités de recherche provient des cotisations de ses organisationsmembres, d'une subvention d'infrastructure du ministère de la Recherche, de la Science et de la Technologie, de même que des subventions et mandats obtenus par ses équipes de recherche.

CIRANO is a private non-profit organization incorporated under the Québec Companies Act. Its infrastructure and research activities are funded through fees paid by member organizations, an infrastructure grant from the Ministère de la Recherche, de la Science et de la Technologie, and grants and research mandates obtained by its research teams.

\section{Les organisations-partenaires / The Partner Organizations}

-École des Hautes Études Commerciales

-École Polytechnique de Montréal

-Université Concordia

-Université de Montréal

-Université du Québec à Montréal

-Université Laval

-Université McGill

-Ministère des Finances du Québec

-MRST

-Alcan inc.

- AXA Canada

-Banque du Canada

-Banque Laurentienne du Canada

- Banque Nationale du Canada

- Banque Royale du Canada

-Bell Canada

-Bombardier

-Bourse de Montréal

-Développement des ressources humaines Canada (DRHC)

-Fédération des caisses Desjardins du Québec

-Hydro-Québec

-Industrie Canada

-Pratt \& Whitney Canada Inc.

-Raymond Chabot Grant Thornton

-Ville de Montréal

Les cahiers de la série scientifique (CS) visent à rendre accessibles des résultats de recherche effectuée au CIRANO afin de susciter échanges et commentaires. Ces cahiers sont écrits dans le style des publications scientifiques. Les idées et les opinions émises sont sous l'unique responsabilité des auteurs et ne représentent pas nécessairement les positions du CIRANO ou de ses partenaires.

This paper presents research carried out at CIRANO and aims at encouraging discussion and comment.

The observations and viewpoints expressed are the sole responsibility of the authors. They do not necessarily represent positions of CIRANO or its partners.

\section{ISSN 1198-8177}




\title{
Models for Bundle Trading in Financial Markets
}

\author{
Jawad Abrache ${ }^{\dagger}$, Teodor Gabriel Crainic ${ }^{*}$, Michel Gendreau*
}

\section{Résumé / Abstract}

Une nouvelle tendance dans les marchés financiers consiste à transiger des valeurs financières sous forme d'ordres composites d'achat et de vente. Nous proposons une nouvelle formulation basée sur les ordres composites du problème d'allocation de valeurs financières. Notre modèle, comparativement à ceux de la littérature, permet une représentation plus détaillée des portefeuilles financiers et la formulation de nouvelles contraintes transactionnelles. Nous présentons en outre une procédure de discrimination d'ordres équivalents sur la base de leur temps de soumission. Les résultats numériques de notre étude permettent d'évaluer empiriquement l'effet « ordres composites », ainsi que la flexibilité et la complexité numérique de notre formulation.

Bundle trading is a new trend in financial markets that allows traders to submit consolidated orders to sell and buy packages of assets. We propose a new formulation for portfolio bundle trading that extends the previous models of the literature through a more detailed representation of portfolios and the formulation of new bidding requirements. We also present post-optimality tie-breaking procedures intended to discriminate equivalent orders on the basis of their submission times. Numerical results evaluate the "bundle" effect as well as the bidding flexibility and the computational complexity of our formulation.

Mots clés: Mécanisme d'enchères, marchés financiers, ordres composites, procédures de discrimination.

Keywords: Auction Design, Financial Markets, Bundle Trading, Discrimination Procedures.

\footnotetext{
† Département d'informatique et recherche opérationnelle, Université de Montréal, Centre de recherche sur les transports, Université de Montréal, C.P. 6128, succursale Centre-ville, Montréal, Canada, H3C 3J7, jawad@crt.umontreal.ca.

† Département management et technologie, Université du Québec à Montréal, Centre de recherche sur les transports, Université de Montréal, C.P. 6128, succursale Centre-ville, Montréal, Canada, H3C 3J7, CIRANO, theo@crt.umontreal.ca.

* Département d'informatique et recherche opérationnelle, Université de Montréal, Centre de recherche sur les transports, Université de Montréal, C.P. 6128, succursale Centre-ville, Montréal, Canada, H3C 3J7, CIRANO, michelg@crt.umontreal.ca.
} 


\section{Introduction}

The emergence of the Internet as a quasi universal medium for trading goods and services has changed in an unpreceded manner the way financial services are offered. The most obvious manifestation of these changes is the phenomenal growth in popularity of online asset trading. More and more individuals and corporate investors have now access to a wide selection of cyber-brokerages that set themselves as an alternative to full-service brokers, a fact that has greatly enhanced competitiveness in the financial services industry and contributed to increase the quality of service and to lower transaction costs.

The most significant changes, however, were probably those that impacted the financial marketplaces themselves. Traditional models of stock markets, which are generally specialistrun, on-the-floor exchanges (the NYSE model), or market-maker, over-the-counter auctions (the NASDAQ model), faced the challenge of Electronic Communications Networks (ECNs). The ECNs are fully-automated, computerized networks that can efficiently match sell and buy orders of financial assets, while offering customers several advantages such as anonymous access and after-hour trading. For traditional financial marketplaces, structural changes (mergers, strategic alliances, etc.) and, most importantly, re-organization of internal policies and procedures were necessary actions for survival. Meanwhile, we witnessed a ressurging interest in auction-based mechanism design for financial marketplaces (e.g., Domowitz 1990 and Madhavan 1992), which seems to reflect a growing awareness that innovative and efficient market mechanisms are key to successful financial marketplaces.

One of the most critical design issues financial marketplaces need to consider is making their procedures reflect as much as possible the bidding needs and requirements of their users. Unfortunately, there is still a large gap between market procedures and what traders may actually want to do in most cases. For instance, while financial portfolios tend to be increasingly more diversified, comprising notably stocks, futures, bonds, and foreign currencies of different kinds, the current organization of financial marketplaces remains heavily sectoral. This fact, combined with the lack of institutionalized links between different marketplaces, increases the dependency of traders with large portfolios on brokerage institutions. Moreover, the fact that most financial marketplaces trade assets on an individual basis makes it difficult for investors to maintain a precise and timely control of the composition of their portfolios. In that regard, a market mechanism based on bundle trading, which would allow traders to submit consolidated orders to sell and buy different quantities of various assets, such that the whole packages are traded, or nothing at all, would be an extremely interesting feature.

Bundle trading is not, strictly speaking, a new concept in financial markets, as its origins could be traced to Markowitz's seminal paper (Markowitz 1952) setting the foundations of modern portfolio selection theory. It is not specific to financial markets, either, since it may be encountered in many other contexts where items of different physical nature are traded and the traders' valuations of a given item depend on whether or not other items are traded as well. In all generality, item interdependency takes two basic forms: two 
items $A$ and $B$ are complementary if the trader's valuation of the bundle $\{A, B\}$ is greater than the valuations of $A$ and $B$ taken separately; they are substitutable if the valuation of $\{A, B\}$ is lower than the valuations of $A$ and $B$ taken separately. The well-known and focal exposure problem (see Rothkopf, Pekeč, and Harstad 1998, for instance) may arise in parallel, combined negotiations in which complementarity effects prevail: one may lose on one item in a desired bundle. Traders are then brought to bid strategically in single-item based auctions, which often results in socially inefficient outcomes. Combinatorial bidding, where bids and allocations are based on bundle of items, alleviates the problem by allowing traders to reflect directly their preferences in the bids they submit.

Other than solving the exposure problem, bundle trading in financial markets has many other potential benefits, that include:

1. Opportunities for cumulative aggregation of value. By submitting consolidated orders, a trader could combine trade orders with very competitive prices (for highly soughtafter assets it desires to sell, for instance) and orders with less competitive prices. Even without taking complementarity effects into consideration, the trader will obviously increase its chances of executing all its orders. Srinivasan, Stallaert, and Whinston (1998) illustrate cumulative value aggregation in Table 1. Here, the trader builds its ask-offer prices on the basis of the last trading day closure prices. If trading were to be done asset by asset, the trader's portfolio would remain over-exposed in the car industry sector and under-exposed in the technology sector. Bundle trading, on the other hand, permits to completely balance the portfolio, even with respect to the worst prices of the day.

\begin{tabular}{|llllll|}
\hline Stock & Quantity & $\begin{array}{l}\text { Yesterday's } \\
\text { close price }\end{array}$ & $\begin{array}{l}\text { Today's price } \\
\text { range }\end{array}$ & Worst price & $\begin{array}{l}\text { Trade } \\
\text { executed? }\end{array}$ \\
\hline IBM & +100 & $743 / 4$ & $751 / 8-755 / 8$ & $755 / 8$ & no \\
Microsoft & +200 & 148 & $1441 / 4-1463 / 4$ & $1463 / 4$ & yes \\
Cisco & +50 & $761 / 8$ & $75-761 / 4$ & $761 / 4$ & yes \\
GM & -200 & $841 / 4$ & $841 / 2-853 / 4$ & $841 / 2$ & yes \\
Ford & -100 & $1221 / 2$ & $1213 / 8-1223 / 8$ & $1213 / 8$ & no \\
Chrysler & -50 & 99 & $983 / 4-1021 / 2$ & $983 / 4$ & yes \\
\hline Bundle & & $68311 / 4$ & & 6750 & yes \\
\hline
\end{tabular}

Table 1: Example of portfolio bundle trading

2. Bundle trading often involves large packages of assets, bringing more liquidity to the marketplace. Concerning this aspect, Popper (1995) reports that, according to brokers' estimates in the UK, the majority of bundle trades customers ask them to realize are worth between $\$ 15 \mathrm{M}$ and $\$ 80 \mathrm{M}$, and huge transactions involving packages of $\$ 1 \mathrm{~B}$ and more are encountered from time to time.

3. Bundle trading should lower commission and transaction fees. Since fund managers and private traders will be able to submit directly their orders to the market, they 
will be less dependent on intermediaries. Moreover, end users retain the largest part of execution risks, and commissions should be lower. Finally, bundle trading generates fewer orders, which means lower operation and administrative costs.

Recent years have seen growing interest in developing and implementing financial market mechanisms based on bundle trading. Among these efforts, Srinivasan, Stallaert, and Whinston (1998) propose a bundle trading market mechanism based on a simple market clearing linear programming formulation. They also discuss the qualitative advantages of bundle trading mechanisms over elaborate trading mechanisms based on single-asset orders, naming the OptiMark Trading System (http://www.optimark.com) as an example. Fan, Stallaert, and Whinston $(1998,1999)$ present FBTS, which is an experimental web-based bundle trading system employing a real-time order matching and execution mechanism. Bossaerts, Fine, and Ledyard (2000) exhibit another advantage of portfolio bundle trading mechanisms. Starting from the observation that thin financial markets often fail to fully equilibrate due to a lack of liquidity (according to the maximum reward/risk ratio criterion of the well-known Capital Asset Pricing Model, Sharpe 1964), the authors experimentally show that implementing a portfolio bundle trading mechanism can "induce" extra liquidity in the market and boost equilibration. Finally, Polk and Schulman (2000) analyze specifically the bond market context and conclude that a proper use of the combined-value logic inherent to bundle trading mechanisms enhances liquidity in that kind of markets.

Generally speaking, bundle trading market mechanisms for financial markets consist of matching algorithms based on simple linear programming formulations to compute allocations and determine payments participants make or receive, such that the economic surplus of the market is maximized. However, these early models are arguably not sophisticated enough to allow traders to control with flexibility the composition of their portfolios after the trade. For example, no known financial e-market model would permit a trader to indicate its willingness to trade a bundle $A$ or a "substitutable" bundle $B$, but not both of them. Another aspect on which the literature has been quite elusive is the post-optimality discrimination of the solutions, when multiple optimal allocations and prices exist. These two issues therefore constitute the core contribution of the present paper. We propose a bundle trading market clearing model in which we introduce new categories of constraints representing various order execution requirements of the traders. We will not try to address the full complexity of a complete bidding vocabulary, but only consider a number of bidding requirements that have special interest in the context of financial markets such as setting limitations on volumes of assets traded in a portfolio, requiring minimal proportions of bundles to be traded, and defining exclusive OR relations between traded bundles. We also present post-optimality tie-breaking procedures intended to discriminate optimal allocations and prices with respect to an "ethical" criterion. Experimental results analyze empirically bundle trading effects from the perspective of economic surplus. They also verify the impact of bidding requirements introduced in our market clearing formulations on allocation complexity and solution times.

The article is organized as follows. In Section 2, we present our market clearing formulations and use dual information to compute acceptable market prices in the continuous case. 
In Section 3, we introduce allocation and price discrimination procedures and prove their validity. Section 4 is devoted to an experimental study. Finally, Section 5 sums up our contribution and discusses directions for future research.

\section{Portfolio Bundle Trading Market Mechanisms}

Bundle trading is best motivated in the context of "end-of-day" re-balancing of financial portfolios. Traders, which are private investors or professional managers of portfolios, need to simultaneously sell and buy various financial assets (stocks, futures, bonds, foreign currencies, etc.) to reflect customer or company guidelines concerning the composition of their portfolios. The structure of current financial marketplaces is nonetheless not well suited to re-balance portfolios, having been designed with other purposes in mind. Hence, traders that want to rebalance their portfolios must be involved in several "combined negotiations", possibly across different marketplaces, and submit bids that are good enough to ensure all the corresponding single-asset trade orders are executed. This practice typically induces important transaction costs, a burdensome and complex strategic analysis, and most importantly, a significant risk to end up with unbalanced portfolios.

Many-to-many, auction-based e-markets that rely on bundle trading offer an interesting alternative. In this market model, traders that are willing to re-balance their portfolios register in an electronic marketplace. A market maker, which may be a human or a virtual software agent, organizes a single-round auction between traders in which it acts as a mediator. Traders submit to the market sealed bundle orders to simultaneously sell and buy different assets, along with maximum prices they are willing to pay or receive if these orders are executed. When they submit their trade orders, traders understand and accept that the market maker may only execute proportions of these orders. After it receives all the orders, the market maker invokes a market clearing mechanism, which consists in an optimization model and an algorithm that solve two problems: the allocation problem and the pricing problem. The allocation problem consists in determining many-to-many sell and buy associations between the traders (matching the bundle orders) and the executed proportion of each order, whereas the pricing problem consists in determining acceptable prices that traders will pay or receive when the trade is completed.

\subsection{The allocation problem}

Prior to presenting formulations of the market clearing allocation problem, we introduce some basic notation and definitions.

Let 
- $I=$ the set of assets traded in the market; and

- $K=$ the set of traders.

Definition 1 (Bundle Order) A bundle order $j$ defined by trader $k \in K$ is submitted to the market as a vector $O_{j}=\left(\left\{q_{j i}\right\}_{i \in I}, p_{j}\right)$ where:

- $q_{j i}$ is the maximum volume of asset $i \in I$ that may be traded in order $j ; q_{j i}>0$ corresponds to a buy order, $q_{j i}<0$ to a sell order, and $q_{j i}=0$ if asset $i$ is not traded in order $j$;

- $p_{j}$ is the maximum (minimum) price trader $k$ is willing to pay (receive) if order $j$ is entirely executed; $p_{j}>0$ if the trader is willing to pay $p_{j}, p_{j}<0$ if the trader is willing to receive $-p_{j}$, and $p_{j}=0$ if the trade is balanced.

A bundle order $j$ is said to be executed in a trade if a positive proportion of the maximum volumes $q_{j i}, i \in I$, requested in order $j$ is traded.

Let also define

- $J_{k}=$ the set of bundle orders formulated by trader $k \in K$;

- $J=\bigcup_{k \in K} J_{k}=$ the set of all bundle orders formulated by traders.

\subsubsection{The basic formulation}

The basic formulation of the allocation problem considers only a minimal set of constraints that express the physical conservation of assets in the trade. Decision variables are:

$$
x_{j}=\text { the traded proportion of bundle order } j, j \in J_{k}, k \in K \text {. }
$$

The allocation problem corresponds in this case to optimization model $(M 1)$ :

$$
\begin{array}{ll}
\max & \sum_{k \in K} \sum_{j \in J_{k}} p_{j} x_{j} \\
\text { s.t. } & \sum_{k \in K} \sum_{j \in J_{k}} q_{j i} x_{j}=0, \quad i \in I \\
& x_{j} \leq 1, \quad j \in J_{k}, k \in K \\
& x_{j} \geq 0, \quad j \in J_{k}, k \in K
\end{array}
$$


Model (M1) is very similar to bundle order matching formulations already proposed by Srinivasan, Stallaert, and Whinston (1998) and Fan, Stallaert, and Whinston (1998). Constraints (2) express the balance of the market: the volume of an asset $i \in I$ that is sold in bundle orders equals the volume that is bought. Constraints (3) define valid traded proportions. The objective reflects the market maker's desire to seek the maximum market surplus, so that highly-priced buy orders (bundle orders with positive limit prices) and lowly-priced sell orders (bundle orders with negative limit prices) are given high execution priority.

\subsubsection{Extensions}

The only element considered thus far in the formulation of the allocation problem from the trader side is the definition of the basic bundle order structure, that is the specification of the maximum volumes of assets to sell and buy, and the limit prices the trader is ready to pay or receive if the order is executed. However, it can safely be assumed that traders would need to formulate more complex trading conditions and requirements. In their simplest form, these requirements directly reflect traders' valuations of single assets and bundles translating, in particular, various complementarity and substitutability relationships. They could also express, however, constraints derived from more elaborate business policies and practices.

Bidding vocabularies (Nisan 2000 and Abrache et al. 2002) address the issue of bidding requirements by providing participants in general combinatorial auctions with the means to define their bids, formulate complex requirements on their execution, and communicate them to the auctioneer. In Abrache et al. (2002), we have proposed a new bidding framework that relies on a two-level representation of a combined bid. At the inner level, atomic bids, which are single-item sell or buy orders, are defined and combined with the help of bidding operators that represent continuous constraints on the traded proportions of atomic bids. So called partial bids created this way are then recursively combined at the outer level with the help of logical bidding operators. In this section, we specifically consider three classes of operators that can be particularly useful in the context of portfolio bundle trading, and we analyze how the corresponding bidding requirements impact the formulation of the allocation problem.

Global upper bounds on the traded volume of an asset. These bounds correspond to limitations (due to internal trading policies, liquidity issues, etc.) traders may have on the total volumes of some assets to be bought or sold as part of a trade. More precisely, let us define:

$$
M_{k i}=\text { the maximum volume of asset } i \text { trader } k \text { is ready to trade. }
$$

A bound $M_{k i}$ adds the following constraint to the formulation of the allocation problem:

$$
\epsilon_{k i} \sum_{j \in J_{k}} q_{j i} x_{j} \leq M_{k i}
$$


where $\epsilon_{k i}=+1$ if the bound corresponds to a buy limitation, and $\epsilon_{k i}=-1$ if the bound corresponds to a sell limitation.

Lower bounds on the traded proportions of an order. There exists circumstances under which traders may consider that a bundle should be executed only if a minimal proportion of the bundle is traded; otherwise, they prefer not to trade the bundle. This is notably the case when fixed-charge execution commissions and fees make execution of marginally small proportions of some orders non profitable. Hence, consider

$$
l_{j}=\text { the minimum proportion of bundle order } j \text { to be executed. }
$$

In order to formulate the bidding conditions corresponding to these bounds, we need to define the following auxiliary binary variables:

$$
y_{j}=1 \text { if bundle order } j \text { is executed, and } y_{j}=0 \text { otherwise. }
$$

Constraints of the allocation problem corresponding to a lower bound $l_{j}$ are then:

$$
l_{j} y_{j} \leq x_{j} \leq y_{j}
$$

Constraints (6) impose that the traded proportion $x_{j}$ of order $j$ be greater than lower bound $l_{j}$ when the order is executed; otherwise, $x_{j}=0$ and nothing at all is traded.

XOR relations. XOR (exclusive OR) relations are best explained with the help of an example. Hence, consider the following trade situation:

\begin{tabular}{|lll|}
\hline Asset & Bundle Order 1 & Bundle Order 2 \\
\hline GM & 1000 (Sell) & \\
Toyota & 200 (Sell) & \\
Ford & & 1500 (Sell) \\
IBM & 1000 (Buy) & \\
AMD & 1000 (Buy) & 2500 (Buy) \\
Cisco & & \\
\hline
\end{tabular}

The trader in this example formulates two "equivalent" trade orders in the sense that both of them sell assets in the automotive sector and buy assets in the technology sector. In order to preserve its portfolios from unnecessary fragmentation, the trader may ask that at most one of the two bundle orders be executed as part of the trade, but without specifying which one.

More generally, we define a XOR relation $\mathcal{X}$, formulated by trader $k$, as a subset of bundle orders in $J_{k}$ which indicates that at most one order in $\mathcal{X}$ should be executed. Let $\mathcal{X}_{k}$ be the set of all XOR relations defined by trader $k, k \in K$. 
The corresponding XOR constraints in the formulation of the allocation problem:

$$
\sum_{j \in \mathcal{X}} y_{j} \leq 1, \quad \mathcal{X} \in \mathcal{X}^{k}, k \in K
$$

In summary, the market-clearing allocation problem can be formulated as model (M2):

$$
\begin{array}{ll}
\max & \sum_{k \in K} \sum_{j \in J_{k}} p_{j} x_{j} \\
\text { s.t. } & \sum_{k \in K} \sum_{j \in J_{k}} q_{j i} x_{j}=0, \quad i \in I \\
& \epsilon_{k i} \sum_{j \in J_{k}} q_{j i} x_{j} \leq M_{k i}, \quad k \in K, i \in I \\
& l_{j} y_{j} \leq x_{j} \leq y_{j} \quad j \in J_{k}, k \in K \\
& \sum_{j \in \mathcal{X}} y_{j} \leq 1, \quad \mathcal{X} \in \mathcal{X}^{k}, k \in K \\
& x_{j} \geq 0, \quad j \in J_{k}, k \in K \\
& y_{j}=\{0,1\}, \quad j \in J_{k}, k \in K
\end{array}
$$

\subsection{The pricing problem}

The pricing problem answers the following question: are there acceptable payments that traders can make or receive such that the market is budget-balanced, that is, the economic surplus is redistributed to the traders? To answer this question, let us consider first in the continuous case the dual $(D 1)$ of the allocation model $(M 1)$ :

$$
\begin{array}{ll}
\min & \sum_{k \in K} \sum_{j \in J_{k}} \mu_{j} \\
\text { s.t. } & \sum_{i \in I} q_{j i} \Pi_{i}+\mu_{j} \geq p_{j}, \quad j \in J_{k}, k \in K \\
& \mu_{j} \geq 0, \quad j \in J_{k}, k \in K
\end{array}
$$

where $\left\{\Pi_{i}\right\}_{i \in I}$ and $\left\{\mu_{j}\right\}_{j \in J_{k}, k \in K}$ are dual variables corresponding to constraints (2) and (3), respectively. Variables $\left\{\Pi_{i}\right\}_{i \in I}$ and $\left\{\mu_{j}\right\}_{j \in J_{k}, k \in K}$ are interesting because of the following result.

Proposition 1 Let $\left\{\Pi_{i}^{\star}\right\}_{i \in I}$ and $\left\{\mu_{j}^{\star}\right\}_{j \in J_{k}, k \in K}$ be optimal solutions of model (D1). Bundle prices $P_{j}=\sum_{i \in I} q_{j i} \Pi_{i}^{\star}, j \in J_{k}, k \in K$ have the following properties: 
(a) When a bundle order $j$ formulated by trader $k$ is executed, i.e., $x_{j}>0$, the payment trader $k$ makes or receives, computed on the basis of the bundle price $P_{j}$, is always at least as good as the trader's limit price $p_{j}$.

(b) Payments determined on the basis of bundle prices $P_{j}, j \in J_{k}, k \in K$, make the market budget-balanced.

Proof. Let $\left\{x_{j}^{\star}\right\}_{j \in J_{k}, k \in K}$ be an optimal solution of the allocation model (M1). Statement (a) of the proposition is a result of complementarity slackness conditions $x_{j}^{\star}\left(p_{j}-\sum_{i \in I} q_{j i} \Pi_{i}\right)=$ $x_{j}^{\star} \mu_{j}^{\star} \geq 0, j \in J_{k}, k \in K$, which is equivalent to $x_{j}^{\star} P_{j} \leq x_{j}^{\star} p_{j}$. Statement (b) follows immediately from constraints (2).

Solving the pricing problem is far more difficult when the general market-clearing model $(M 2)$ is considered. In fact, due to non-convexities introduced by constraints corresponding to lower bounds and XOR relations, there is even an issue of the existence of acceptable market clearing prices. This issue is beyond the scope of the present paper. We point, however, to some interesting research avenues in Section 5.

\section{Discrimination Procedures}

A practical problem may arise when the market mechanism determines an optimal market clearing allocation and a set of acceptable prices: what happens if the allocation, or the prices, or both of them, are not unique? This issue of uniqueness is particularly critical in the context of financial markets where the market maker should provide traders with a satisfactory justification of the auction outcomes. Therefore, since an arbitrary choice between possibly multiple optimal solutions is clearly unacceptable, what is required is a discrimination procedure based on "ethical" criteria.

Submission time of bundle orders is such a criterion that can reasonably be used to separate equivalent orders. Suppose for instance that two traders $A$ and $B$ submit one bundle order each. Trader $A$ sends bundle order $O_{A}$, which is received by the market maker at time $t$, and trader $B$ sends bundle order $O_{B}$ that the market maker receives later, at time $t^{\prime}>t$. On the basis of the submission time criterion, trader $A$ has got an advantage. In this case, discriminating between traders $A$ and $B$ means that, if there are multiple optimal solutions, the market maker will use the following choice strategy:

1. Ensure that the selected optimal allocation gives the largest volume possible to trader $A$ that submitted the earliest bid.

2. Guarantee trader $A$ of getting as much pricing "reward" as possible from the trade, that is, paying the less if it buys and receiving the most if it sells. 
Lexicographical orderings of optimal solutions conceptualize best allocation and price preferences on the basis of submission time. Denote by $t_{j}$ the submission time of order $j$, $j \in J$. Suppose that the submission times of any two orders can be compared in a strict way $\left(t_{j_{1}}>t_{j_{2}}\right.$ or $\left.t_{j_{2}}>t_{j_{1}}, \forall j_{1}, j_{2} \in J, j_{1} \neq j_{2}\right)$. We may also suppose with no loss of generality that the ordering of the index set of orders $J$ is the same as that of submission times, that is, $j_{1}>j_{2} \equiv t_{j_{1}}>t_{j_{2}}, \forall j_{1}, j_{2} \in J$.

Definition 2 (Primal lexicographical ordering) Let $X^{(1)^{\star}}=\left\{x^{(1)^{\star}}\right\}_{j \in J_{k}, k \in K}$ and $X^{(2)^{\star}}=$ $\left\{x^{(2)^{\star}}\right\}_{j \in J_{k}, k \in K}$ be two different optimal allocations (i.e., optimal solutions of model (M1)). We say that $X^{(1)^{\star}}$ is lexicographically better than $X^{(2)^{\star}}$ with respect to submission times, and denote $X^{(1)^{\star}} \succ_{\mathbf{P}} X^{(2)^{\star}}$, if there exists $j \in J$ such that

$$
\begin{aligned}
& \text { 1. } x_{j^{\prime}}^{(1)^{\star}}=x_{j^{\prime}}^{(2)^{\star}}, \forall j^{\prime} \leq j-1 \text {; and } \\
& \text { 2. } x^{(1)^{\star}}>x^{(2)^{\star}}{ }_{j} \text {. }
\end{aligned}
$$

In other terms, the optimal allocation $X^{(1)^{\star}}$ is lexicographically better than the optimal allocation $X^{(2)^{\star}}$ with respect to submission times if there exists an index $j^{\prime}$ such that the $j^{\prime t h}$ order has a larger execution proportion in $X^{(1)^{\star}}$ than in $X^{(2)^{\star}}$, while the first $j^{\prime}-1$ orders have equal execution proportions in $X^{(1)^{\star}}$ and $X^{(2)^{\star}}$. A similar definition can be proposed for a dual lexicographical ordering, where bundle prices are compared instead of execution proportions.

Definition 3 (Dual lexicographical ordering) Let $Y^{(1)^{\star}}=\left[\left\{\Pi^{(1)^{\star}}\right\}_{i \in I},\left\{\mu^{(1)^{\star}}\right\}_{j \in J_{k}, k \in K}\right]$ and $Y^{(2)^{\star}}=\left[\left\{\Pi^{(2)^{\star}}\right\}_{i \in I},\left\{\mu^{(2)^{\star}}\right\}_{j \in J_{k}, k \in K}\right]$ be two different optimal set of prices (i.e., dual solutions of model (M1)), and consider bundle prices computed on the basis of $Y^{(1)^{\star}}$ and $Y^{(2)^{\star}}$, that $i s, P_{j}^{(1)}=\sum_{i \in I} q_{j i} \Pi^{(1)^{\star}}{ }_{i}, P_{j}^{(2)}=\sum_{i \in I} q_{j i} \Pi^{(2)^{\star}}{ }_{i}, j \in J_{k}, k \in K$. We say that $Y^{(1)^{\star}}$ is lexicographically better than $Y^{(2)^{\star}}$ with respect to submission times, and denote $Y^{(1)^{\star}} \succ_{\mathbf{D}} Y^{(2)^{\star}}$, if there is $j \in J$ such that

$$
\begin{aligned}
& \text { 1. } P_{j^{\prime}}^{(1)}=P_{j^{\prime}}^{(2)}, \forall j^{\prime} \leq j-1 \text {; and } \\
& \text { 2. } P_{j}^{(1)}>P_{j}^{(2)} \text {. }
\end{aligned}
$$

We next propose a post-optimality procedure (Algorithm 1) that discriminates optimal allocations of model $(M 1)$ using lexicographical ordering $\succ_{\mathbf{P}}$. Let $\mathcal{P}$ denote the polyhedron that represents the set of optimal allocations of model $(M 1)$. The procedure consists in a search algorithm that works on the vertices of $\mathcal{P}$. Starting at an arbitrary vertex of $\mathcal{P}$, which corresponds to a basic optimal solution of $(M 1)$, the algorithm constructs a sequence of vertices of $\mathcal{P}$ in which a move from a vertex to the next one is done similarly to the simplex algorithm, 
and in such a way that ordering $\succ_{\mathbf{P}}$ is improved. In practice, these moves correspond to (degenerate) pivots, driven by $\succ_{\mathbf{P}}$, of the simplex method. Once the algorithm is unable to locally improve the current optimal solution with respect to $\succ_{\mathbf{P}}$, it returns it as the best allocation found.

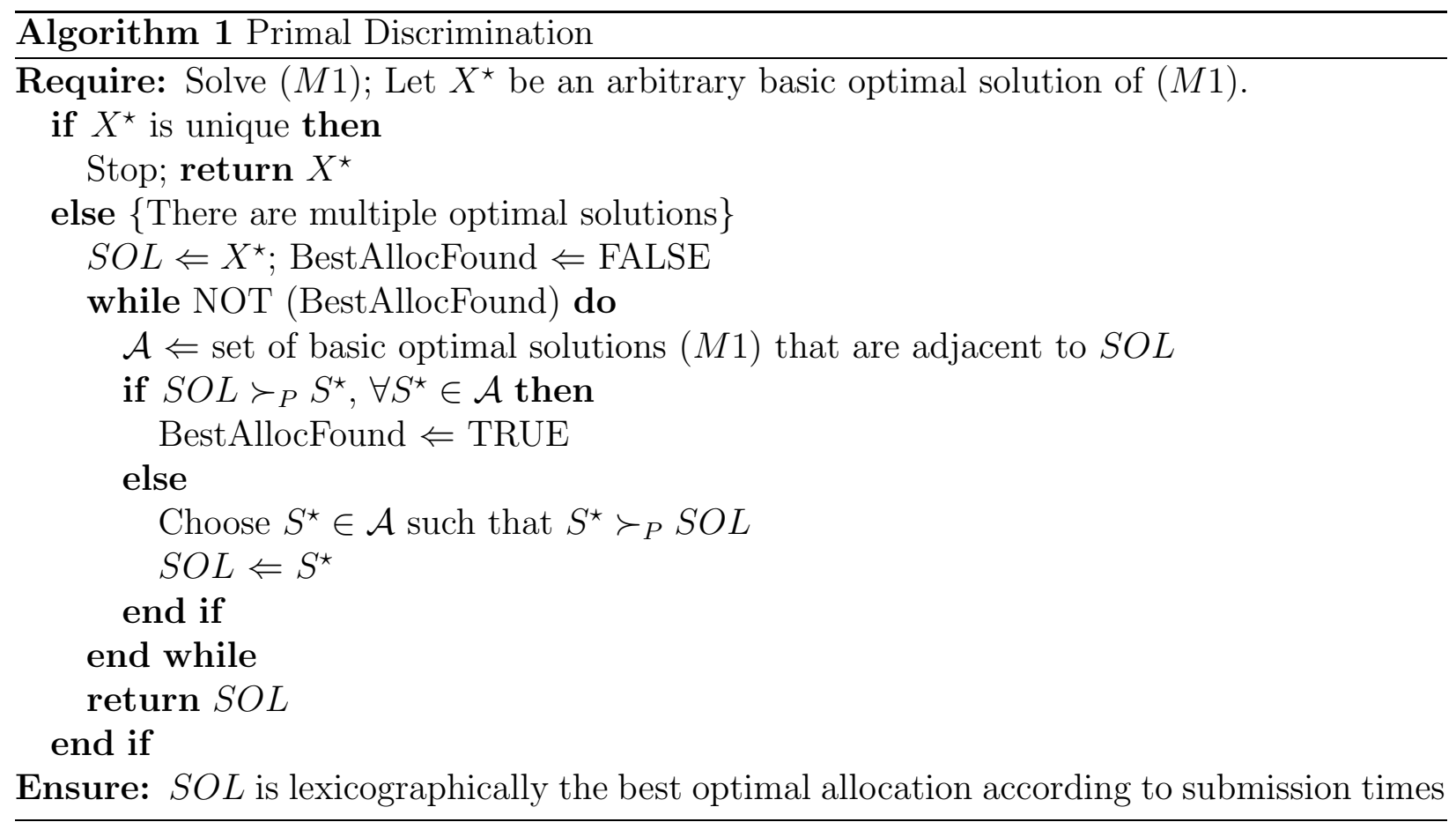

We now proceed to prove the validity of the primal discrimination procedure. But let us first consider the following result.

Lemma 1 Let $\mathcal{P}$ be a polytope (bounded polyhedron) and $x^{0}$ a vertex of $\mathcal{P}$. Suppose there are $l$ other vertices of $\mathcal{P}, x^{1}, \ldots, x^{l}$ that are adjacent to $x^{0}$. Now consider $x^{l+1}$, a vertex of $\mathcal{P}$ that is not adjacent to $x^{0}$. Then, there exists $z=\lambda x^{l+1}+(1-\lambda) x^{0}, 0<\lambda<1$ such that $z \in \mathcal{P}^{\prime}=\operatorname{CONV}\left(x^{0}, \ldots, x^{l}\right)$.

Proof. Consider polyhedron $\mathcal{R}$ defined by vertex $x^{0}$ and extremal rays $r^{i}=x^{i}-x^{0}, 1 \leq i \leq l$, that is $\mathcal{R}=\left\{x: x=x^{0}+\sum_{1 \leq i \leq l} \alpha_{i} r^{i}, \alpha_{i} \geq 0,1 \leq i \leq l\right\}$. We have indeed that $\mathcal{P} \subset \mathcal{R}$ : if $\{x: A x \leq b\}$ is a representation of $\mathcal{P}$, then $\mathcal{R}$ is the intersection of all half-spaces defined by facets of $\mathcal{P}$ that are binding at $x^{0}$. Hence, there exist $\alpha_{1}, \ldots, \alpha_{l} \geq 0$, such that $x^{r+1}=$ $x^{0}+\sum_{1 \leq i \leq l} \alpha_{i} r^{i}$, and $\sum_{1 \leq i \leq l} \alpha_{i}>0$ since $x^{r+1} \neq x^{0}$. Consider now $z=\lambda x^{r+1}+(1-\lambda) x^{0}$. It is easy to verify that if $0<\lambda \leq \frac{1}{\sum_{1 \leq i \leq l} \alpha_{i} r^{i}}$, then $z \in C O N V\left(x^{0}, \ldots, x^{l}\right)$.

Proposition 2 The discrimination procedure of Algorithm 1 terminates after a finite number of iterations, and provides an optimal solution that is lexicographically the best with respect to submission times. 
Proof. Consider the polytope $\mathcal{P}$ of optimal solutions of model $(M 1)$. It is easy to verify that the discrimination procedure terminates in a finite number of iterations: at an optimal solution $S O L$, either the algorithm moves to an adjacent basic solution that is lexicographically better than $S O L$, or it returns $S O L$ as the best solution found. Since there is a finite number of basic solutions of $(M 1)$, the algorithm cannot improve indefinitely optimal solutions with respect to lexicographical ordering $\succ_{P}$.

We need to prove that $S O L$, the optimal solution the algorithm returns, is really the best according to lexicographical ordering $\succ_{P}$. First, we note that no basic optimal solution of (M1) that is adjacent to $S O L$ is better than $S O L$ with respect to $\succ_{P}$. Suppose now that $x^{1}, \ldots, x^{l}$ are basic optimal solutions adjacent to $S O L$, and there exists $x^{l+1}$, an optimal basic solution that is not adjacent to $S O L$, which verifies $x^{l+1} \succ_{P} S O L$. According to Lemma 1, there exists $z=\lambda x^{l+1}+(1-\lambda) S O L, 0<\lambda<1$, such that $z \in \mathcal{P}^{\prime}=C O N V\left(S O L, x^{1}, \ldots, x^{l}\right)$. It is easy to establish that $z \succ_{P} S O L$. On the other hand, since $S O L \succ_{P} x^{i}, \forall i, 1 \leq i \leq l$, then $\forall i \in\{1, \ldots, l\}, \exists j_{i}^{\prime} \in J$, such that $S O L_{j}=x_{j}^{i}, \forall j \leq j_{i}^{\prime}-1$, and $S O L_{j_{i}^{\prime}}>x_{j_{i}^{\prime}}^{i}$. Now, if $j_{\text {min }}=\min \left\{j_{i}^{\prime}\right\}_{1 \leq i \leq l}$, then $S O L_{j}=z_{j}, \forall j \leq j_{\text {min }}-1$, and $S O L_{j_{\min }}>z_{j_{\min }}$, which contradicts the previous statement that $z \succ_{P} S O L$. Therefore, $S O L$ is the best basic optimal solution according to lexicographical ordering $\succ_{P}$, and overall the best optimal solution since all optimal solutions in $\mathcal{P}$ can be represented as convex combinations of basic optimal solutions of $\mathcal{P}$.

The dual discrimination procedure presented in Algorithm 2 is quite similar to the primal procedure of Algorithm 1. The only differences are that the dual procedure works on the space of the dual optimal solutions of model $(M 1)$ and relies on lexicographical ordering $\succ_{D}$ to separate optimal set of prices.

\section{Experimental Analysis}

In this section, we present the main numerical results and conclusions of our computational study. The experiments involved several data sets corresponding to instances of bundle trading allocation models $(M 1)$ and $(M 2)$. Each data set comprised several series of randomly generated test problems, with the following characteristics: 200 to 2000 assets in 27 different sectors, 100 traders, and up to 40 bundle orders per trader. All computational testing was carried out on a SUN Enterprise 10000, with SunOS 5.8 as the operating system. Test problems generation procedures and the allocation problem solution algorithms were coded in $\mathrm{C}++$, and used the ILOG CPLEX 7.1 MIP solver callable library, with no particular parameter tuning.

The experiments were conducted with two objectives in mind. We first intended to measure the "bundle effect" in the basic allocation model ( $M 1)$. A formulation of traditional singleasset market clearing mechanisms is thus required as a benchmark. In that regard, we adopted a simple "disaggregation" approach that consists in decomposing each bundle order 


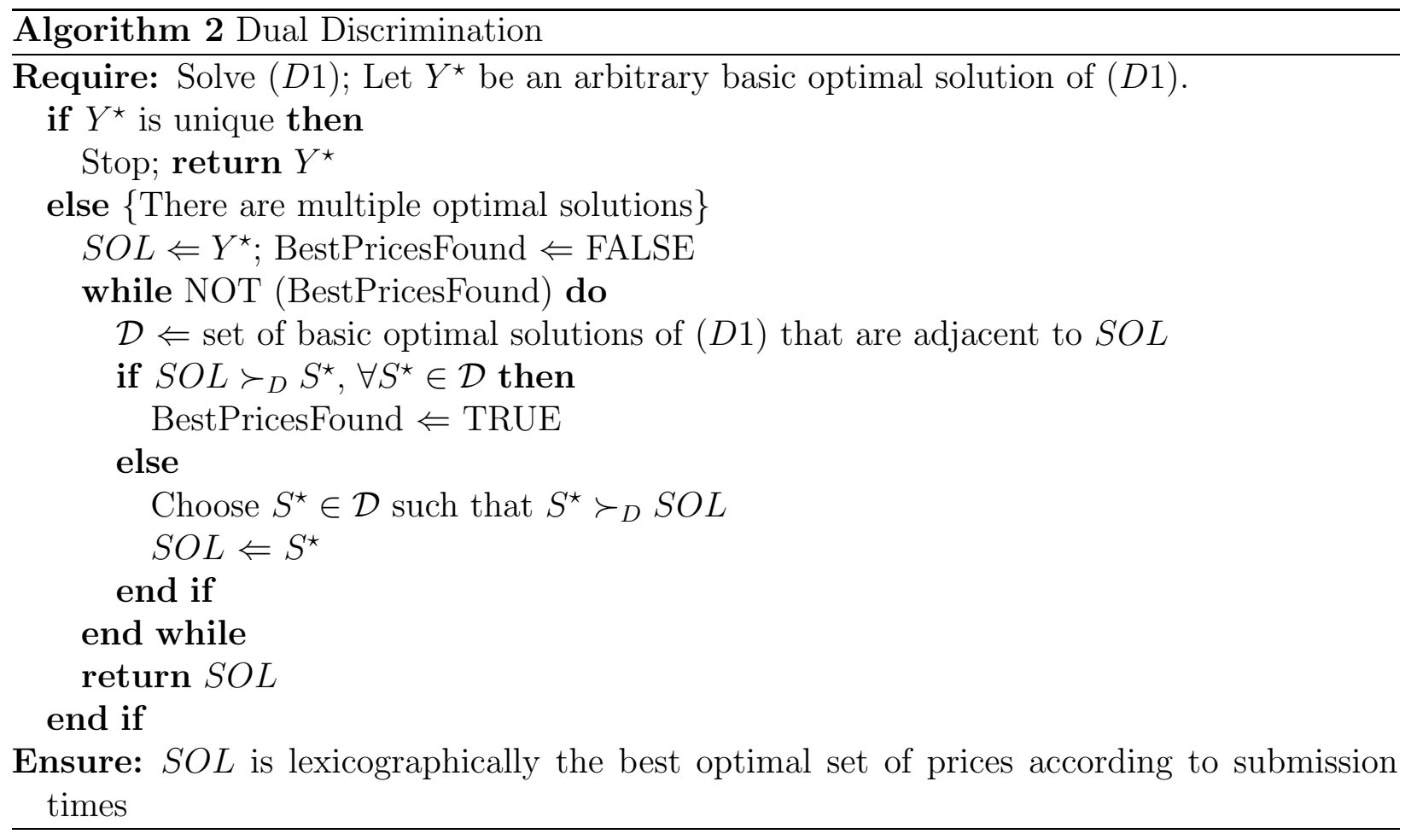

into its elementary components, that is, the single-asset sell and buy orders from which the bundle is made. The resulting formulation preserves the main trading objectives of each trader, but does not consider complementarity and substitutability effects and also relaxes the requirement that sell and buy orders in a same bundle must be executed in equal proportions. Comparisons between model $(M 1)$ and the single-asset formulation relied on two evaluation metrics: 1) the total economic surplus achieved by the market, and 2) the number of cumulative value aggregation occurrences, which are the cases where a trader obtains better execution proportions on some of the assets it desires to sell or buy when a bundle-based market clearing formulation is used instead of single-asset allocation. We also investigated how various parameters of the allocation problem (number of assets and orders, bundle size, etc.) influence the efficiency of the market mechanisms.

Our second objective was to estimate, from economic and algorithmic perspectives, the impact of additional bidding requirements introduced in the combinatorial market clearing formulation (M2). We focused on lower bounds and XOR relations and considered instances of model (M2) in which constraints corresponding to one or the other of these two classes of requirements are generated. We then measured relative gains or losses in economic surplus, this time using the basic allocation model $(M 1)$ as the reference formulation. We also report integrality gaps and CPU solution times of the corresponding MIP problems, which help gain insights about the allocation complexity of model (M2). 


\subsection{Basic formulation problems}

DATASET-1 consists of several series of test problems that correspond to the basic bundlebased market clearing formulation (M1). The structure of these problems is shown in Table 2. Each series is made of 150 test problems, equally distributed in three bundle size classes: problems with small bundle orders (3 to 5 assets), medium bundles (10 to 20 assets), and large bundles (30 to 50 assets).

\begin{tabular}{c|cccc}
\hline Problem & \multicolumn{4}{|c}{ Problem description } \\
\cline { 2 - 5 } series & \#assets & \#traders & \#orders per trader & (\#assets/\#orders) ratio \\
\hline$S_{B}-01$ & 200 & 100 & 3 & $2 / 3$ \\
$S_{B}-02$ & 300 & 100 & 4 & $3 / 4$ \\
$S_{B}-03$ & 400 & 100 & 5 & $4 / 5$ \\
$S_{B}-04$ & 400 & 100 & 10 & $2 / 5$ \\
$S_{B}-05$ & 500 & 100 & 10 & $1 / 2$ \\
$S_{B}-06$ & 1000 & 100 & 15 & $2 / 3$ \\
$S_{B}-07$ & 1000 & 100 & 20 & $1 / 2$ \\
$S_{B}-08$ & 2000 & 100 & 30 & $2 / 3$ \\
$S_{B}-09$ & 2000 & 100 & 40 & $1 / 2$ \\
\hline
\end{tabular}

Table 2: DATASET-1 - Basic bundle trading allocation problems

The results of the experiments run on DATASET-1 problems are summarized in Figure 1. We measured the ratio of the economic surplus achieved by the bundle-based market mechanism to the one of the corresponding single-asset benchmark formulation, and took the average of that ratio over the 50 problems in each class of each problem series. This measure is intended to give a rough indication of how market liquidity compares among the two market models. Our main observation is that the market liquidity of the bundle-based mechanism is poor in general, as the average ratio is always below $30 \%$. We also note that bundle size and the (\#assets/\#orders) ratio of the number of assets traded in the market to the total number of orders submitted by traders are the two factors that significantly influence market liquidity: the more small bundles are submitted to the market, the higher is the economic surplus achieved. On the other hand, cumulative value aggregation occurs quite frequently (for $64 \%$ of the submitted orders on average) and seems not to depend on bundle size or the (\#assets/\#orders) ratio. 

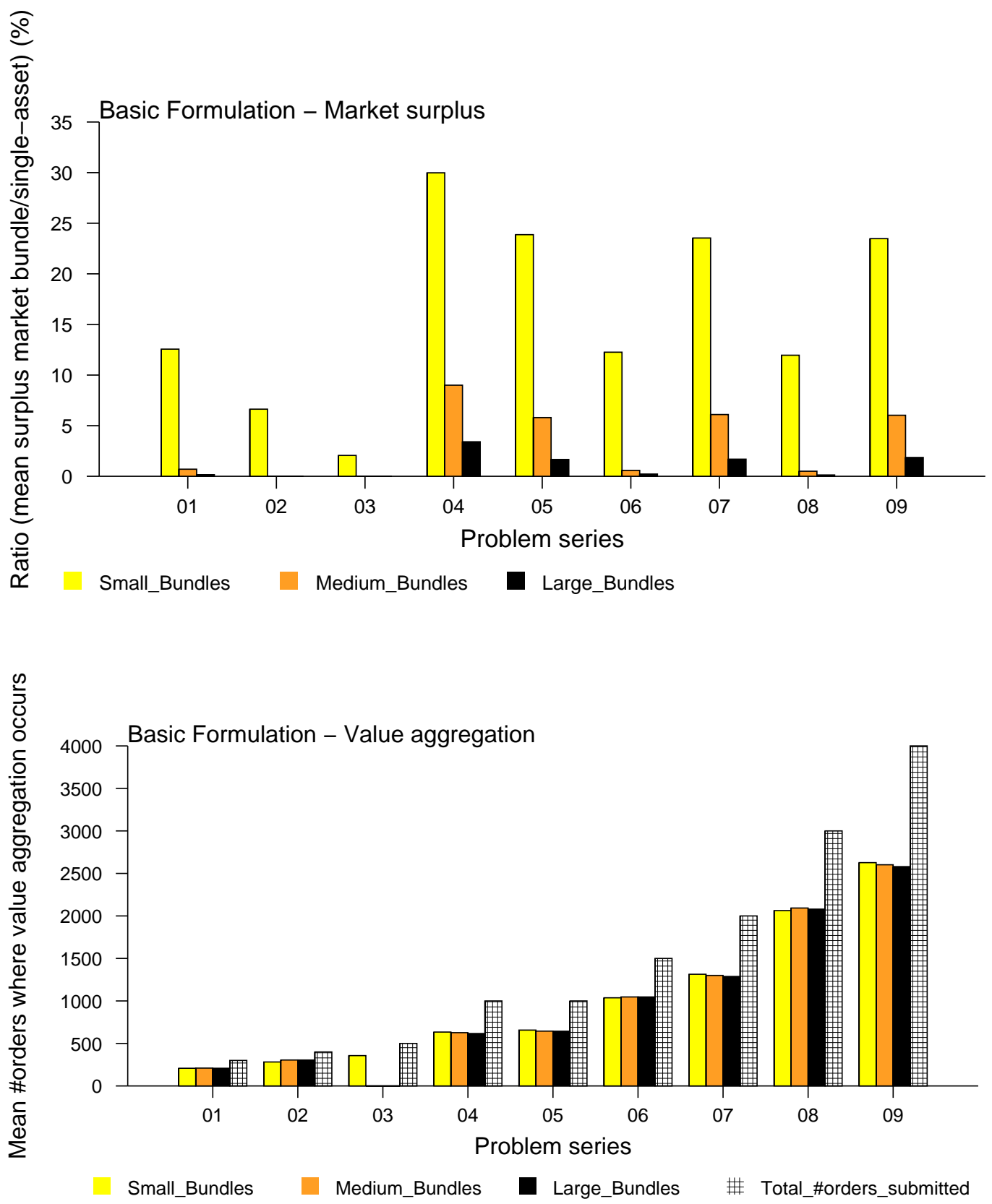

Figure 1: DATASET-1: Market surplus and cumulative value aggregation 


\subsection{Lower bounds and XOR problems}

Table 3 presents DATASET-2, which displays the attributes of the instances of the combinatorial market clearing model (M2) with lower bounds. Two additional parameters have been taken into account when lower bound problems are generated. $F_{L B}$ is the generation frequency of lower bounds, and indicates the probability that a lower bound is attached to a bundle order, whereas $L B_{\max }$ is the maximum value (comprised between 0 and 1 ) that a lower bound can take. Therefore, lower bounds are generated according to a Bernoulli probability law and their value is uniformly distributed in the range $\left[0, L B_{\max }\right]$.

\begin{tabular}{c|ccccc}
\hline \multirow{2}{*}{$\begin{array}{c}\text { Problem } \\
\text { series }\end{array}$} & \multicolumn{5}{|c}{ Problem description } \\
\cline { 2 - 6 } & \#assets & \#traders & \#orders per trader & $F_{L B}$ & $L B_{\max }$ \\
\hline$S_{L B}-01$ & 200 & 100 & 3 & $1 / 10$ & 0.2 \\
$S_{L B}-02$ & 500 & 100 & 10 & $1 / 10$ & 0.2 \\
$S_{L B}-03$ & 1000 & 100 & 20 & $1 / 10$ & 0.2 \\
\hline$S_{L B}-04$ & 200 & 100 & 3 & $1 / 10$ & 0.9 \\
$S_{L B}-05$ & 500 & 100 & 10 & $1 / 10$ & 0.9 \\
$S_{L B}-06$ & 1000 & 100 & 20 & $1 / 10$ & 0.9 \\
\hline$S_{L B}-07$ & 200 & 100 & 3 & $1 / 3$ & 0.2 \\
$S_{L B}-08$ & 500 & 100 & 10 & $1 / 3$ & 0.2 \\
$S_{L B}-09$ & 1000 & 100 & 20 & $1 / 3$ & 0.2 \\
\hline$S_{L B}-10$ & 200 & 100 & 3 & $1 / 3$ & 0.9 \\
$S_{L B}-11$ & 500 & 100 & 10 & $1 / 3$ & 0.9 \\
$S_{L B}-12$ & 1000 & 100 & 20 & $1 / 3$ & 0.9 \\
\hline
\end{tabular}

Table 3: DATASET-2 - Lower bounds allocation problems

XOR relations formulate traders' bidding requirements on the execution of "equivalent" bundle orders. A complete characterization of that equivalence relationship is a difficult task that relies on the good understanding of the traders' profile, the objectives that drive their trade activities in the market, etc. Notwithstanding its importance, this issue is well beyond the scope of our study, and we will rather limit ourselves to simple empirical techniques to generate XOR relations. One of these techniques, which we call asset-switching, can be described as follows. Given a bundle order $O_{j}=\left(\left\{q_{j i}\right\}_{i \in I}, p_{j}\right)$, an asset $i_{0} \in I$ that belongs to activity sector $A$ and which is traded in $O_{j}\left(q_{j i_{0}}>0\right.$, for instance) is arbitrarily selected. Asset-switching consists here in choosing an asset $i_{1} \in I$ that also belongs to activity sector $A$ but is not traded in $O_{j}$, and building a new bundle $O_{j^{\prime}}=\left(\left\{q_{j^{\prime} i}\right\}_{i \in I}, p_{j^{\prime}}\right)$ such that $q_{j^{\prime} i_{0}}=0$, $q_{j^{\prime} i_{1}}>0$, and $q_{j^{\prime} i}=q_{j i_{0}}, \forall i \in I$, s.t. $i \neq i_{0}, i \neq i_{1}$. Computation of $p_{j^{\prime}}$ and $q_{j^{\prime} i_{1}}$ is carried out such that orders $O_{j}$ and $O_{j^{\prime}}$ have approximately equivalent monetary values and some predefined conditions on demand and supply of assets in the portfolio are satisfied. Finally, a XOR relation $\mathcal{X}$, involving bundle orders $O_{j}$ and $O_{j^{\prime}}$, is generated. The process may be easily extended to generate XOR relations between more than two bundle orders.

DATASET-3, which structure is shown in Table 4, is a set of problem series that represent instances of model $(M 2)$ with XOR relations. Parameter $F_{X O R}$, which varies in the table 
between $1 / 10$ and $3 / 4$, denotes the generation frequency of XOR constraints.

\begin{tabular}{c|cccc}
\hline \multirow{2}{*}{$\begin{array}{c}\text { Problem } \\
\text { series }\end{array}$} & \multicolumn{4}{|c}{ Problem description } \\
\cline { 2 - 5 } & \#assets & \#traders & \#orders per trader & $F_{X O R}$ \\
\hline$S_{X O R}-01$ & 200 & 100 & 3 & $1 / 10$ \\
$S_{X O R}-02$ & 500 & 100 & 10 & $1 / 10$ \\
$S_{X O R}-03$ & 1000 & 100 & 20 & $1 / 10$ \\
\hline$S_{X O R}-04$ & 200 & 100 & 3 & $1 / 3$ \\
$S_{X O R}-05$ & 500 & 100 & 10 & $1 / 3$ \\
$S_{X O R}-06$ & 1000 & 100 & 20 & $1 / 3$ \\
\hline$S_{X O R}-07$ & 200 & 100 & 3 & $3 / 4$ \\
$S_{X O R}-08$ & 500 & 100 & 10 & $3 / 4$ \\
$S_{X O R}-09$ & 1000 & 100 & 20 & $3 / 4$ \\
\hline
\end{tabular}

Table 4: DATASET-3 - XOR allocation problems

Figure 2 represents average integrality gaps and CPU solution times of lower bound problems in DATASET-2. Due to the special structure of lower bounds in formulation (M2), the integrality gap also indicates the relative "loss" in economic surplus when lower bounds are taken into account. Several factors seem to influence integrality gaps. Hence, we observe that problems with smaller number of assets and large bundle sizes are more sensitive to lower bounds. The relative difference of the three integrality gap figures (corresponding to small, medium, and large bundle problems) also indicates that allocation problems become more constrained as bounds become larger and more often included in bundles. CPU solution times, as expected, grew exponentially with the number of assets. In that regard, problems with larger bundles were also significantly more costly to solve, which is consistent with our previous integrality gap observations.

We define the economic gap as the additional market surplus when XOR relations are generated and taken into consideration in the allocation model (M2). Average economic gaps over DATASET-3 problems are represented in Figure 3. While XOR relations clearly enhance the bidding flexibility from the trader perspective, they also significantly impact the market behavior through high levels of additional liquidity induced in the marketplace. Economic gaps are, of course, more important when the generation frequency of XOR relations is high, but also seem to be more pronounced in problems with larger bundles. As for integrality gaps and CPU times depicted in Figure 4, they broadly follow the same tendencies reported for lower bound problems. It is however interesting to note that, while integrality gaps are relatively small (below 15\%), the problems are nevertheless as costly to solve to optimality as lower bound problems. 


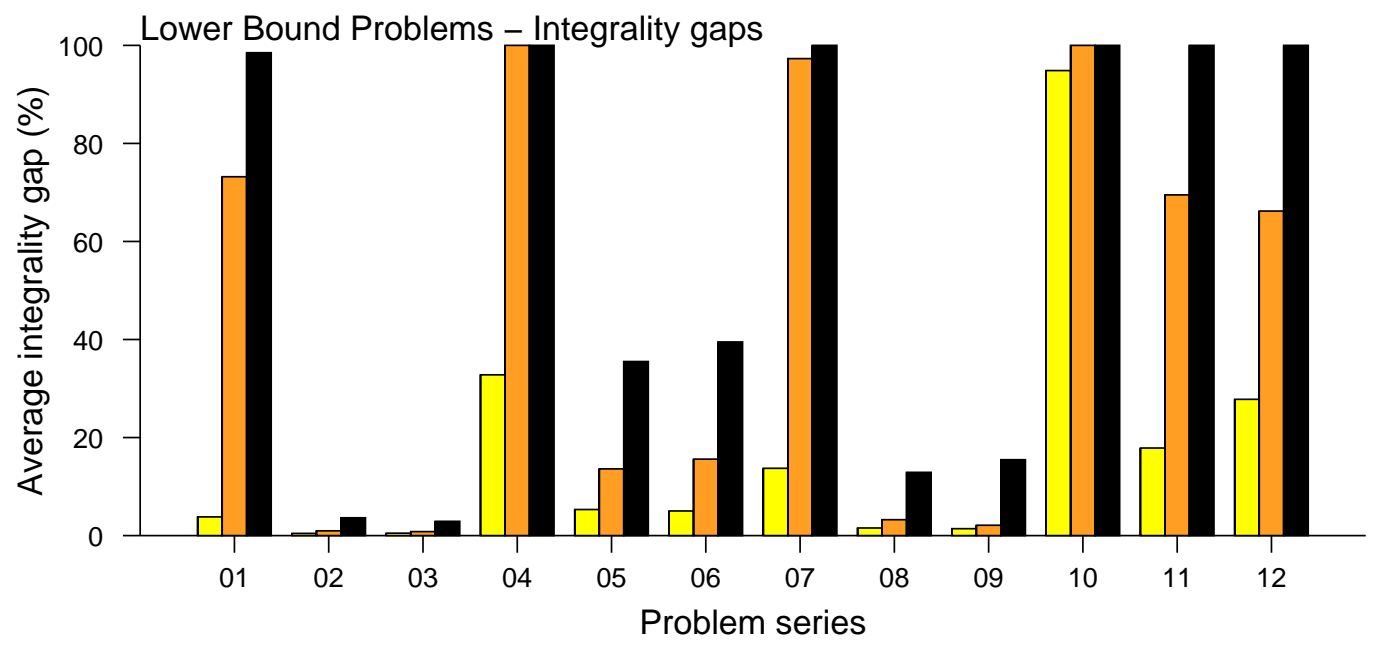

Small_Bundles Medium_Bundles $\square$ Large_Bundles

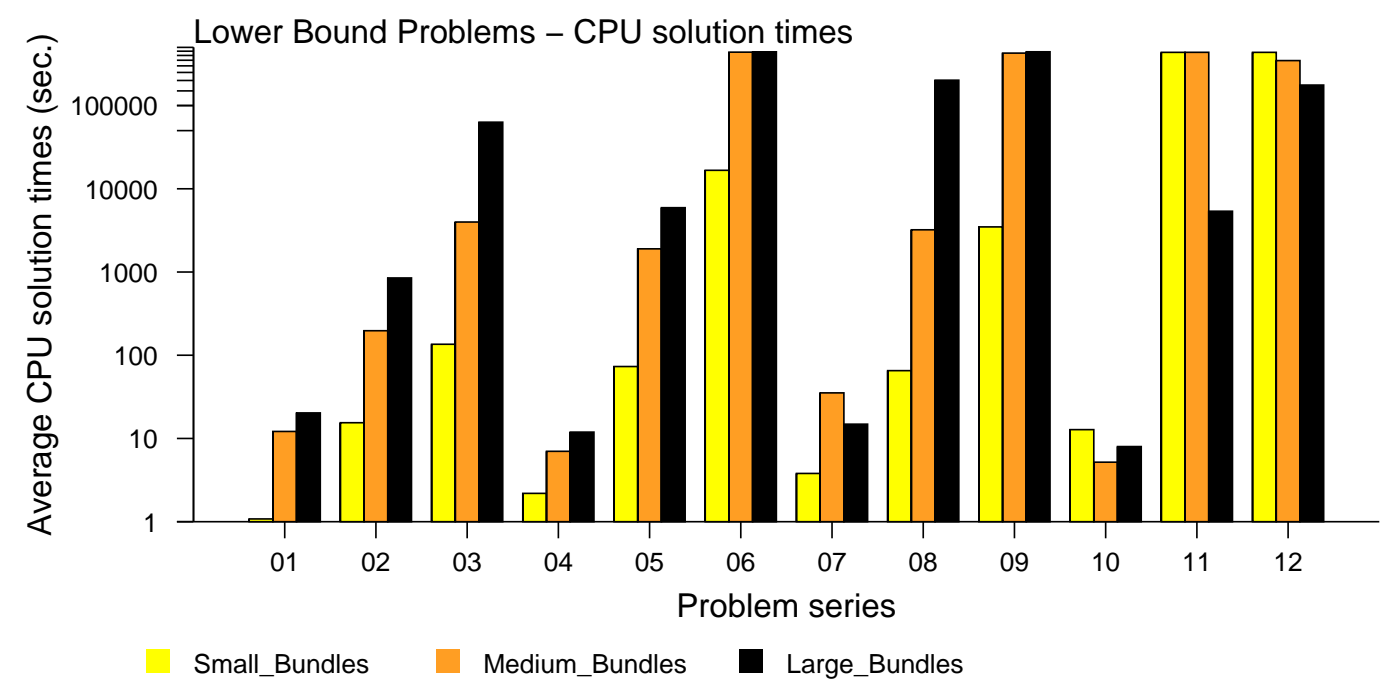

Figure 2: Integrality gaps and CPU times for DATASET-2 test problems 


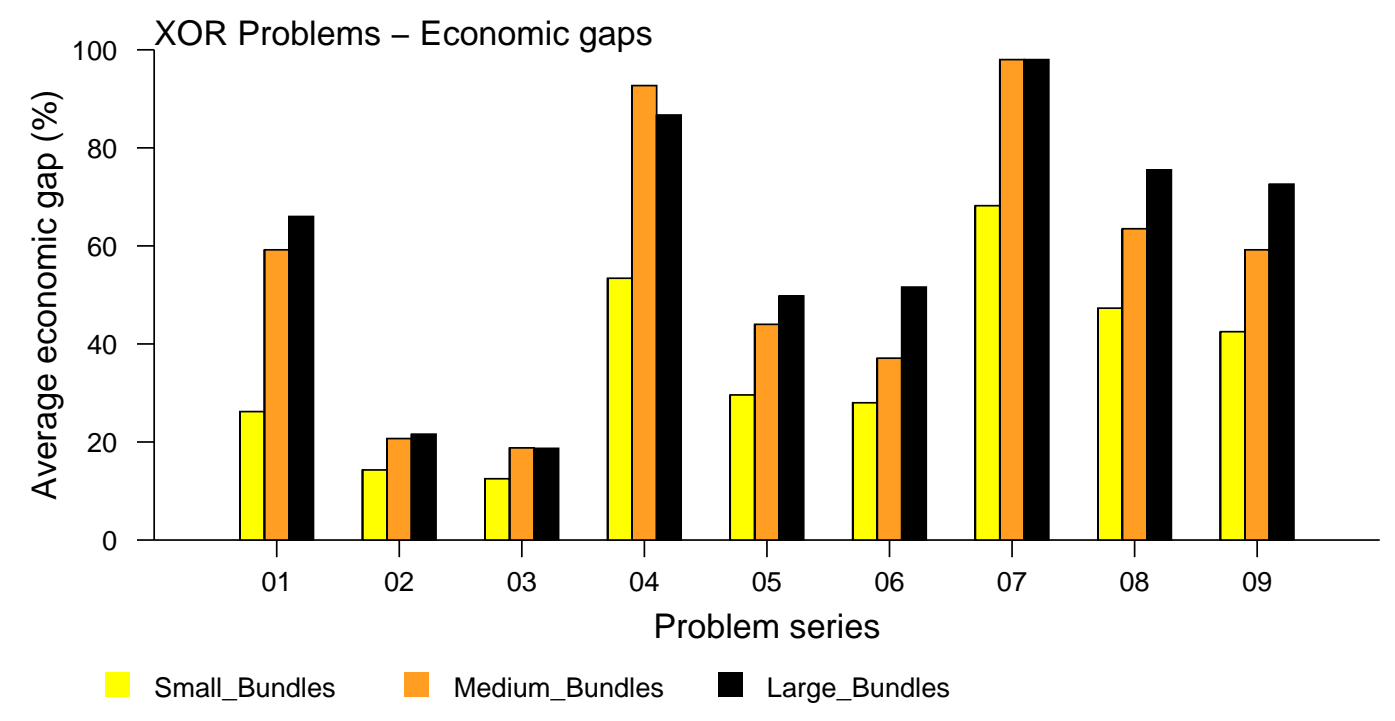

Figure 3: Economic gaps of DATASET-3 test problems

\section{Concluding Remarks}

In this paper, we have presented a new bundle-based market clearing allocation model for financial marketplaces. Our formulation introduced classes of constraints that correspond to various bidder trading requirements. We have focused on three bidding operators that allow traders to set limitations on volumes of assets to be traded and on bundle execution proportions, as well as to define exclusive OR execution relations between "equivalent" bundles. We believe that, despite being very simple, these requirements are particularly important in the context of portfolio bundle trading, as they make it possible for traders to design more elaborate bidding strategies and enhance considerably the accuracy of their control over the composition of their portfolios. The experimental study examined continuous and combinatorial variants of the market clearing model and verified the impact of several parameters of the allocation problems on allocation efficiency and computational complexity. Among the important findings of this study is the fact that bundle trading mechanisms, by their very nature, improve bidders' chances of balancing portfolios but achieve relatively poor market surplus, which makes them appealing for private, inter-institution secondary markets specifically intended to realize portfolio re-balancing operations. We have furthermore confirmed that additional bidding requirements, especially XOR relations, can also have a significant economic impact on market surplus.

The combinatorial bundle-based market clearing formulation (M2) raises theoretical and practical challenging issues. First of all, solutions times for large problems (1000 assets and more) have been huge (in the day order), which is clearly inappropriate for a mechanism supposed to run at least once a day and stresses out the necessity to develop more efficient 


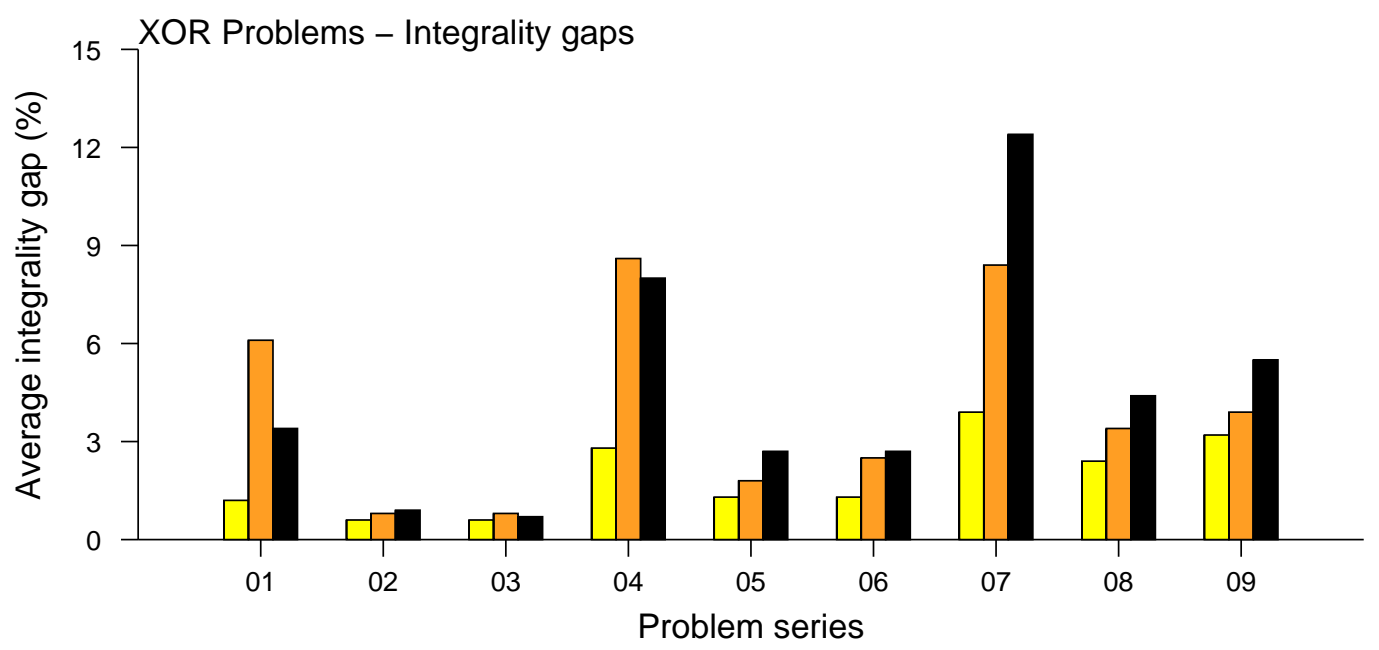

$$
\text { Small_Bundles } \square \text { Medium_Bundles } \quad \text { Large_Bundles }
$$

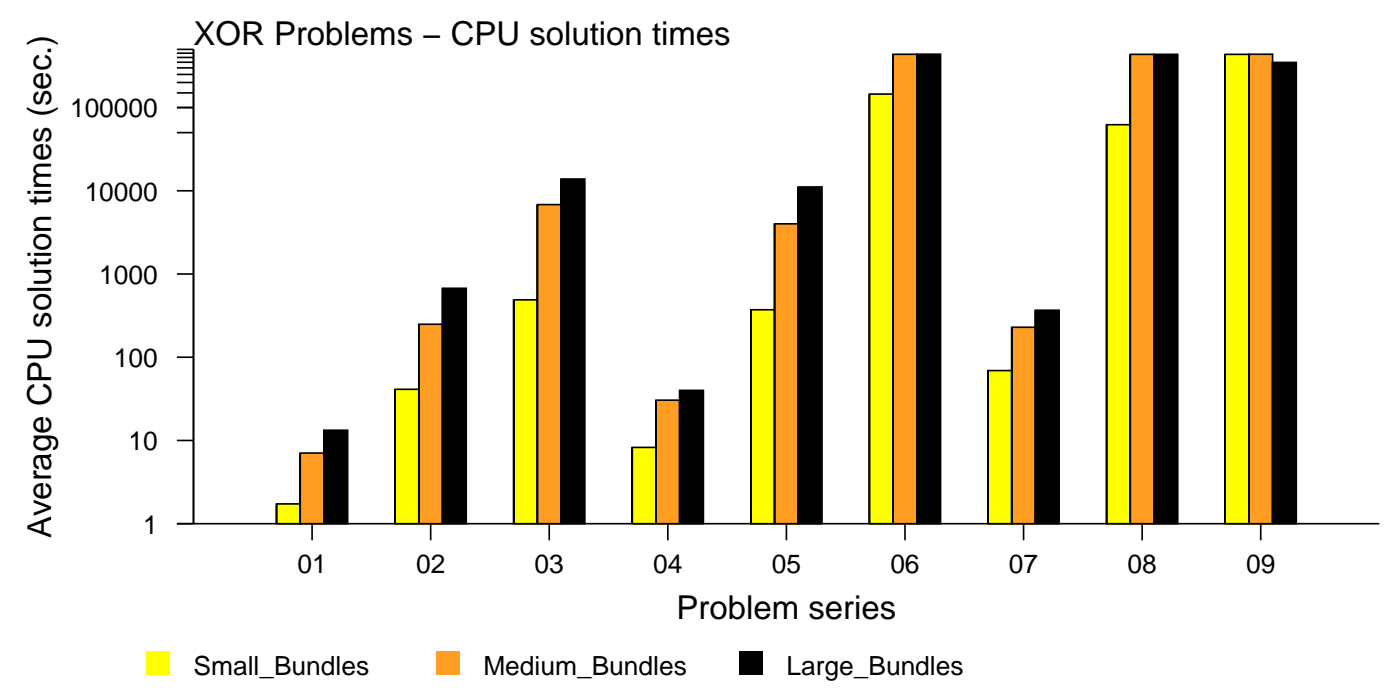

Figure 4: Integrality gaps and CPU times for DATASET-3 test problems 
solution methods. The existence of budget-balance prices that are acceptable to traders and their computation in the combinatorial case is another difficult problem. Vickrey-based payments could be a promising avenue. In that regard, Parkes, Kalagnanam, and Eso (2001) have adapted the classical Vickrey-Clarke-Groves pricing mechanism (Vickrey 1961, Clark 1971, Groves 1973) for exchanges involving heterogeneous non-divisible items to achieve budget-balance. We believe that their approach can be readily extended to divisible items.

We are also much interested in evaluating bundle trading market mechanisms over longer periods of time. Concerning this aspect, simulation techniques can be extremely valuable in creating controlled environments for manipulating market conditions and trader profiles regarding asset preference, risk aversion, bid sophistication, and so on.

\section{Acknowledgment}

This project has received financial support from the Bell Canada University Laboratories (LUB), the Natural Sciences and Engineering Research Council of Canada through its Basic Research and Collaborative Industry-University Research grant programs, the FCAR research development fund of the Province of Québec, and the Valorisation-Recherche Québec fund.

We would like to think our colleagues Jacques Robert, Yves Richelle, Martin Boyer, and Robert Gérin-Lajoie for valuable discussions on the matter of this paper. We also express our gratitude to Zine Khelil who helped in conducting the numerical tests.

\section{References}

Abrache, J., Bourbeau, B., Crainic, T.G., and Gendreau, M. (2002). A New Bidding Framework for Combinatorial E-Auctions. Publication CRT-2002-19, Centre de recherche sur les transports, Université de Montréal, Canada.

Bossaerts, P., Fine, L., and Ledyard, J. (2000). Inducing Liquidity in Thin Financial Markets through Combined-Value Trading Mechanisms. Working paper, Caltech.

Clarke, E.H. (1971). Multipart Pricing of Public Goods. Public Choice, 11:17-33.

Domowitz, I. (1990). The Mechanics of Automated Trade Systems. Journal of Financial Intermediation, 1:167-194.

Fan, M., Stallaert, J., and Whinston, A.B. (1998). The Design and Development of a Financial Cybermarket Based on a Bundle Trading Mechanisms. Working paper, Center for Research on Electronic Commerce, The University of Texas, Austin, TX. 
Fan, M., Stallaert, J., and Whinston, A.B. (1999). A Web-based Financial Trading System. IEEE Computer.

Groves, T. (1973). Incentives in Teams. Econometrica, 41:617-631.

Madhavan, A. (1992). Trading Mechanisms in Securities Markets. Journal of Finance, 47(2):607-641.

Markowitz, H. (1992). Portfolio Selection. Journal of Finance, 7(1):77-91.

Nisan, N. (2000). Bidding and Allocation in Combinatorial Auctions. In Procedings of the ACM Conference on Electronic Commerce, pages 1-12. ACM 2000, Minneapolis, MN.

Parkes, D.C., Kalagnanam, J., and Eso, M. (2001). Achieving Budget-Balance with VickreyBased Payment Schemes in Exchanges. In Proc. 17th International Joint Conference on Artificial Intelligence.

Polk, C.W. and Schulman, E. (2000). Enhancing the Liquidity of Bond Trading. In The Handbook of Fixed-Income Technology. Summit Group Press, New York.

Popper, M. (1995). The Ins and Outs of Portfolio Trading. Global Investor, pages 18-20.

Rothkopf, M.H., Pekeč, A., and Harstad, R.M. (1998). Computationally manageable combinatorial auctions. Management Science, 44:1131-1147.

Sharpe, W.F. (1964). Capital Asset Prices: A Theory of Market Equilibrium Under Conditions of Risk. Journal of Finance, 19(3):425-442.

Srinivasan, S., Stallaert, J., and Whinston, A.B. (1998). Portfolio Trading and Electronic Networks. CREC working paper, University of Texas at Austin.

Vickrey, W. (1961). Conterspeculation, Auctions, and Competitive Sealed Tenders. Journal of Finance, 16:8-37. 